\title{
Postpartum modern contraceptive use in northern Ethiopia: prevalence and associated factors - methodological issues in this cross-sectional study
}

\author{
Kamyar Mansori ${ }^{1,2}$, Shiva Mansouri Hanis ${ }^{3}$, Fatemeh Khosravi Shadmani ${ }^{4}$ \\ 'Social Development and Health Promotion Research Center, Gonabad University of Medical Sciences, Gonabad, Iran; ${ }^{2}$ Department of \\ Epidemiology, School of Public Health, Iran University of Medical Sciences, Tehran, Iran; ${ }^{3}$ School of Public Health, Dezful University of Medical \\ Sciences, Dezful, Iran; ${ }^{4}$ Department of Epidemiology, School of Public Health, Shahid Beheshti University of Medical Sciences, Tehran, Iran
}

\section{Dear Editor,}

We read the paper entitled 'Postpartum modern contraceptive use in northern Ethiopia: prevalence and associated factors', written by Abraha et al. [1], which was published in Epidemiology and Health in March 2017. The aim of the study was to assess postpartum modern contraceptive use and associated factors among postpartum women in northern Ethiopia. A multivariable logistic regression model showed that the following independent variables were the most important determinants of postpartum modern conception use in the town of Aksum: maternal educational level (secondary and tertiary education level), family planning counseling during pregnancy and during prenatal and postnatal care, having postnatal care, resuming sexual activity, menses returning after birth, and experiencing problems with previous contraceptive use [1]. However, although this research was valuable and the results are interesting, some methodological issues should be considered relating to this cross-sectional study.

Regardless of the results obtained from the model, it should be explained that accurate predictors or determinants of a dependent variable cannot be reliably identified by a cross-sectional study because predictors must be identified based on cohort studies $[2,3]$. In other words, predictive or casual inferences cannot be made from cross-sectional studies because of the associations between

\section{Correspondence: Fatemeh Khosravi Shadmani}

Department of Epidemiology, School of Public Health, Shahid Beheshti University of Medical Sciences, Velenjak St., Shahid Chamran Highway, Tehran 1983963113, Iran

E-mail:khosravishadman@gmail.com

This article is available from: http://e-epih.org/

(c) This is an open-access article distributed under the terms of the Creative Commons Attribution License (http://creativecommons.org/licenses/by/4.0/), which permits unrestricted use, distribution, and reproduction in any medium, provided the original work is properly cited.

(C) 2017, Korean Society of Epidemiology variables measured at the same time point in such studies. Without the temporality assumption (the dependent variable must occur after the independent variable) there is no way of determining whether a factor is a risk factor, is predictive/causal, or is a consequence of the outcome [4]. Therefore, longitudinal studies are essential for developing assumptions to be used in clinical prediction models, whereas in this study [1], a cross-sectional study was used to identify the independent predictors of postpartum modern contraceptive use. Therefore, it is essential to interpret the results of this study in light of the above explanation.

\section{CONFLICT OF INTEREST}

The authors have no conflicts of interest to declare for this study.

\section{ORCID}

Kamyar Mansori: http://orcid.org/0000-0001-5008-8547; Shiva Mansouri Hanis: http://orcid.org/0000-0001-7107-4996; Fatemeh Khosravi Shadmani: http://orcid.org/0000-0002-5172-7950

\section{REFERENCES}

1. Abraha TH, Teferra AS, Gelagay AA. Postpartum modern contraceptive use in northern Ethiopia: prevalence and associated factors. Epidemiol Health 2017;39:e2017012.

2. Steyerberg EW. Clinical prediction models: a practical approach to development, validation, and updating. Dordrecht: Springer; 2008, p. 38

3. Ayubi E, Sani M. Carotid atherosclerosis is associated with left ventricular diastolic function: methodological issue. J Echocardiogr 2016;14:181.

4. Kamper SJ, Hancock MJ, Maher CG. Optimal designs for prediction studies of whiplash. Spine (Phila Pa 1976) 2011;36:S268-S274. 


\title{
Postpartum modern contraceptive use in northern Ethiopia: prevalence and associated factors - methodological issue in this cross-sectional study
}

\author{
Teklehaymanot Huluf Abraha' ${ }^{1}$, Alemayehu Shimeka Teferra ${ }^{2}$, Abebaw Addis Gelagay ${ }^{3}$ \\ ${ }^{1}$ Department of Public Health, College of Health Sciences, Aksum University, Aksum, Ethiopia; ${ }^{2}$ Department of Epidemiology and Biostatistics, \\ College of Medicine and Health Sciences, University of Gondar, Gondar, Ethiopia; ${ }^{3}$ Department of Reproductive Health, College of Medicine and \\ Health Sciences, University of Gondar, Gondar, Ethiopia
}

\begin{abstract}
We greatly respect the comments made by the above readers of our article, as they have precisely pointed out a methodological limitation of our design. We certainly recognize this study design limitation. In our nation (Ethiopia), the prevalence and associated factors of postpartum contraceptive use have not yet been assessed. Therefore, we as the authors of this study believe that assessing the magnitude of modern contraceptive use and its determinants using a cross-sectional study design is very important in the study
\end{abstract} area.

Moreover, cross-sectional studies provide an ample data that are useful for planning health services and medical programs. Our study measured the prevalence of postpartum modern contraceptive use (48.0\%), and examined the relationship between the outcome variable (postpartum modern contraceptive use) and associated factors as they existed in the defined population at a particular time. However, a longitudinal study would not address the prevalence. The interpretation of the results of this article does not change based on this aspect of our research. Despite this limitation of the study design (i.e., the fact that it lacks a temporal rela- tionship), we believe that the advantages of a cross-sectional study design outweigh its limitations. We also believe that this limitation can be overcome in the near future by changing the study design. Moreover, we as the authors have addressed this issue in our research objectives.

The main objective of our article was to assess the prevalence and associated factors of modern contraceptive use in the town of Aksum, northern Ethiopia. We, the authors, are confident that the many scholars who are readers of this journal will find value in our article.

\section{CONFLICT OF INTEREST}

The authors have no conflicts of interest to declare for this study.

\section{ORCID}

Teklehaymanot Huluf Abraha: http://orcid.org/0000-0003-08681659

5

\footnotetext{
Correspondence: Teklehaymanot Huluf Abraha

Department of Public Health, College of Health Sciences, Aksum

University, P.O. Box 1010, Aksum, Ethiopia

E-mail: teklehaymanothuluf@gmail.com

This article is available from: http://e-epih.org/

(C) This is an open-access article distributed under the terms of the Creative Commons Attribution License (http://creativecommons.org/licenses/by/4.0/), which permits unrestricted use, distribution, and reproduction in any medium, provided the original work is properly cited.
}

(C) 2017, Korean Society of Epidemiology 